\title{
Yield QTL affected by heading date in Mediterranean grown barley
}

Alfonso Cuesta-Marcos ${ }^{1,2}$, Ana M. Casas ${ }^{1}$, Patrick M. Hayes ${ }^{2}$, M. Pilar Gracia ${ }^{1}$, José M Lasa ${ }^{1}$, Francisco Ciudad $^{3}$, Primitiva Codesal $^{3}$, José L Molina-Cano ${ }^{4}$, Ernesto Igartua ${ }^{1}$

${ }^{1}$ Department of Genetics and Plant Production, Aula Dei Experimental Station, CSIC, P.O. Box 202, E-50080 Zaragoza, Spain

${ }^{2}$ Department of Crop and Soil Science, Oregon State University, Corvallis, OR 97331, USA

${ }^{3}$ ITA, Instituto de Tecnología Agraria, Junta de Castilla y León, P.O. Box 172, E-47071, Valladolid, Spain

${ }^{4}$ Field Crops, IRTA, Av. Rovira Roure 191, E-25198 Lleida, Spain 


\section{Abstract}

2

Knowledge regarding QTL has led to remarkable advances in breeding for a variety of

4 traits, some of which have an effect on yield under particular environmental conditions.

5 However, the same yield QTL are not usually found, even in the same population tested in

6 different environments, as a result of large genotype-by-environment interactions. In this

7 study we aimed at identifying yield QTL in a series of experiments carried out in Spain. We

8 used a barley doubled haploid population derived from a spring by winter cross. The

9 relationship between heading date and yield, and between the principal heading date QTL and

10 yield, changed depending on the environment. Allelic combinations causing early or late

11 heading dates usually did not favour high yield, whereas intermediate heading dates were

12 associated with higher variability, but also higher yield potential. To identify QTL for grain

13 yield independent of heading date, the population was divided into three classes: Early,

14 Intermediate, and Late. We found three new QTL affecting yield only at specific maturity

15 groups. The implications of these findings in relation to barley breeding are discussed.

16

17 Keywords: Barley, yield, heading date, QTL, Mediterranean 
The final yield of a crop is the product of multiple growth and development processes that occur throughout the life cycle, with many genes having direct and indirect effects (Slafer 2003). QTL determining favourable traits for particular environmental conditions may also

4 have indirect effects on yield; examples include dwarfism (Rebetzke et al., 2000) and photoperiod response (Laurie et al., 1994; Worland et al., 1998. It stands to reason, therefore, that many QTL would be detected for grain yield. Indeed, many have been detected in multiple barley populations (reviewed by Thomas 2003), but few have had direct impact on breeding programmes, at least as gathered from published sources. Among the causes for this lack of successful application of QTL information to MAS are genetic background, genotypeby-environment $(\mathrm{GxE})$ interaction, and the modest effects of yield QTL alleles (Voltas et al. 2002, Slafer 2003). GxE interactions are one of the main obstacles to progress in breeding programmes. Therefore, elucidation of the processes determining yield GxE, and their genetic basis, would be of great help to breeders.

Phenological adjustment is one of the key factors determining adaptation under water limiting conditions, and it is one of the main contributors to GxE interaction in cereals. The main factors driving barley phenology are photoperiod and vernalization sensitivity. Both have a direct influence on crop adaptation and the geographic distribution of cultivars (Boyd 1996). Flowering time genes determine the duration of crop developmental phases and, indirectly, the production of dry matter, the number of structures that contribute to final yield (tillers, spikes and grains), and also the way in which dry matter is partitioned (Boyd 1996). Karsai et al. (1999) showed that Ppd-H1 and Vrn-H1, the two major genes affecting flowering time in the Dicktoo x Morex population, had also a significant effect on several agronomic traits including yield components.

The aim of this research was to discover grain yield QTL in a doubled haploid population of barley that is agronomically well-adapted to the inland plains of Spain. We 
1 were particularly interested in the relationship between heading date and yield, as manifested

2 by GxE and its effects on QTL estimation.

\section{Materials and Methods}

Plant Material

The population under study was a set of 120 doubled-haploid (DH) lines derived from the F1 of Beka x Mogador. Beka (Bethge XIII x Kneifel) is a spring habit variety and Mogador (Alpha x Sonja) is a winter. This population was developed in the framework of the Spanish Barley Breeding Programme and is well-adapted and agronomically relevant to Northern Spain.

\section{Field Trials}

We carried out five autumn-sown field trials at four locations representative of the main barley growing areas of Northern Spain (Table 1). The experiments are coded with two letters indicating the province (i.e. HU - Huesca, LE - Lleida, VA - Valladolid, ZA - Zaragoza) and the last two digits of the harvest year $(2001,2002,2003)$. wide. Crop husbandry followed local practices at each location. Experimental design at each trial was an alpha lattice with three replicates. Days to heading were recorded at all locations,

21 except LE02, as the number of days between January $1^{\text {st }}$ and the day when approximately 2 $22 \mathrm{~cm}$ of awns were visible on $50 \%$ of the inflorescences in each plot. The grain yield data, 23 based on the harvest of each $7.2 \mathrm{~m}^{2}$ or $9 \mathrm{~m}^{2}$ plot, was converted to kilograms per hectare. 


\section{Genotyping and linkage map construction}

Genotyping and linkage map construction procedures are described in detail in Cuesta-

Marcos et al. (2008). Briefly, genotyping was carried out with 215 markers: 10 RFLP, 5 STS,

15 RAPD, 112 AFLP and 73 SSR (15 ESTs and 58 genomic-derived markers). Map density

for QTL analysis was reduced to a minimum of $1.5 \mathrm{cM}$ between markers, by removing cosegregating markers (similarity higher than 0.95 ) and those with poor goodness of fit. The final map for QTL analysis had 126 markers distributed over 7 linkage groups.

9

\section{QTL analysis}

QTL main effects analysis was performed using the composite interval mapping (CIM) procedure (Zeng 1994), implemented in Windows QTL Cartographer 2.5 (Wang et al. 2005). We chose up to 21 cofactors for each CIM analysis, using a stepwise regression procedure with a significance threshold of 0.05 . Walk speed was set to $2 \mathrm{cM}$, and the scan window to 10 $\mathrm{cM}$ beyond the markers flanking the interval tested. Experiment-wise significance $(\alpha=0.05)$ likelihood ratio test (LR) thresholds for QTL were determined with 1000 permutations, and expressed as LOD score (LOD $=0.217$ LR). Epistatic interactions between QTL were evaluated with the Multiple Interval Mapping (MIM, Kao et al. 1999) tool implemented in Windows QTL Cartographer using Bayesian Information Criterion (BIC-M0).

Tests for QTL-by-environment interactions (QTLxE) were performed using the GxE option of the multitrait mapping method of Jiang and Zeng (1995) that is implemented in Windows QTL Cartographer 2.5. CIM and IM (Interval Mapping, Lander and Botstein 1989). Cofactors were selected manually, and markers closest to the yield and heading date QTL were included. The significance threshold was set using 1000 permutations $(\alpha=0.05)$ for the IM LOD scores. The coefficient of determination from the multilocus model (MIM) that 
1 included the significant QTL and the significant interactions among them, was used to

2 describe the proportion of the total variance of grain yield explained by QTL. Combined

3 analyses of variance of the GxE and QTLxE interactions were also performed. The joint error

4 for these analyses was the mean of the errors of the single trials.

To identify the QTL involved in the interaction of yield with early maturity, we classified the population by the parental alleles (coded as B or M) at the two principal loci governing heading date: Bmag382 (Ppd-H2 region) and Bmac132 (Eam6 region) (CuestaMarcos et al. 2008). This classification produced three maturity groups: Early (BM), Intermediate (BB or $\mathrm{MM}$ ) and Late (MB). A new factor (Cycle) with these three levels was created in order to account for maturity. Subsequent analyses of variance were performed, with Cycle forced into the model. Factors jointly accounting for each marker main effect and its interaction with Cycle, were sequentially added to the model, one at a time. At each step, the marker whose factor explained a larger percentage of the sums of squares was kept in the model. This procedure was repeated sequentially, for all markers except for those located in the Eam6 and Ppd-H2 regions, until no new factors explained a significant amount of the genotype sums of squares.

These analyses of variance were performed using the GLM procedure of SAS v9 (SAS Institute Inc., Cary, NC, USA). Genotypes were considered random factors (representative of the population of possible lines from this cross) and environments were considered fixed

21 (because of the low number of degrees of freedom). The error for the combined analysis of 22 variance of the genotype main effects (including QTL markers) was the Genotype-byEnvironment (GXE) term. 


\section{Yield and heading date}

Progeny yields were, on average, closer to the best parent for each trial. The ranges of variation for grain yield and days to heading for the $\mathrm{DH}$ lines were greater than the

6 differences between the parental lines (Beka and Mogador), showing transgressive segregation in all the experiments (Table 2). A detailed description of the heading date data is presented in Cuesta-Marcos et al. (2008). Regarding overall yield, LE01, LE02 and VA02 showed similar average values, and amplitudes in the range of variation, whereas ZA01 and LE02 were significantly lower and higher yielding, respectively (Table 2).

The relationship between heading date and yield showed different trends in the four experiments in which both variables were recorded (Fig. 1). At LE01, yield decreased with lateness, and the opposite was true at VA02. At the other two trials, though the slope was negative, the relationship was non-significant. Overall, the plot of the averages of the 120 lines for yield and heading date across environments showed a slightly quadratic pattern (Fig. 2), with the highest yielding lines, and also the largest variability for yield, occurring at intermediate heading dates (Fig. 2).

\section{QTL main effects and interactions}

Five QTL for grain yield were found when analyzing the average yield of the $120 \mathrm{DH}$

21 lines. Three of them were on the long arm of chromosome 5H (Fig. 3a). These QTL, coded as Y1-Y5, explained $40 \%$ of the phenotypic variation for the trait (Table 3). For four of these QTL, higher grain yield was associated with the Mogador allele. The exception was Y3,

24 where higher yield was due to the Beka allele. A significant interaction between Y2 and Y4 
1 was responsible for an additional $5 \%$ of the phenotypic variation (Table 3 ). Only one of the

2 grain yield QTL (Y2) showed significant QTL x Environment interaction (Fig. 3b).

Two additional regions with strong QTLxE interaction were detected on the long arm of

4 chromosome $1 \mathrm{H}$, and in the centromeric region of chromosome $2 \mathrm{H}$ (Fig. 3b). These two regions coincide with the positions of the two major QTL for heading date under autumnsown conditions in this population (Cuesta-Marcos et al. 2008): one associated with Ppd-H2 (Bmag382) and the other with Eam6 (Bmac132). The QTLs in these regions explained between 48 and $64 \%$ of the phenotypic variation in heading date variation in this population (Cuesta-Marcos et al. 2008). Therefore, the genotype by environment interaction for grain yield detected in this population was, in part, caused by the dynamic relationship between yield and heading date across environments and planting dates (Figs. 1 and 2).

To further understand these interactions, we studied the effects of these loci in each experiment (Fig. 4). Early alleles (Mogador for Bmac132, Beka for Bmag382) were significantly superior in the experiment in which earlier lines showed a yield advantage (LE01). The opposite was true for the trial in which later lines had higher yields (VA02). Bmag337 showed large and contrasting effects in four trials

Because the relationship between heading date and yield changed with maturity group, we asked the question 'are yield QTL in the full population the same as those within each maturity group?' We hypothesized that any QTL whose effect was apparent only for a specific maturity group would show significant interaction with the principal QTL 21 determining maturity ( $\mathrm{Ppd}-\mathrm{H} 2$ and Eam6 regions). The three maturity groups showed significantly different heading dates (Table 4). Yields were highest for the intermediate class, although only the late lines were significantly different. The analyses of variance designed to discover QTL concealed by QTLXE interaction, due to the effect of the two principal heading 
1 markers with significant effects on yield were identified, all of them on chromosome $4 \mathrm{H}$ 2 (HvM40, HvZCCT, E41M47-d).

We found that the effects of the QTL detected in the overall analysis were not consistent

4 across maturity groups (Fig 5). The averages of the absolute values for the additive effects for

5 all seven loci were 49, 80 and $67 \mathrm{~kg} \mathrm{ha}^{-1}$ for the Early, Intermediate, and Late classes, respectively. A majority of markers (6 out of 7) showed significant effects in the Intermediate class, whereas only 1 and 2 were significant in the Early and Late classes, respectively (Fig. 5). The effects of both HvM40 and HvZCCT on yield were apparent in the Intermediate

9 heading class only. The effect of E41M47-d was important in the Late heading class, and negligible in the other two classes. The four QTL already detected in the full population analysis $(Y 1, Y 2, Y 4, Y 5)$ showed effects across the maturity groups, but were most important in the Intermediate class.

\section{Discussion}

Yield levels were average for VA02 and ZA01, and moderately high for LE01, LE02 and HU03 when compared with historic averages. Therefore, the data are representative. Mogador was higher yielding than Beka in most trials (Table 2). The only exception was ZA01, and this may be explained by a lack of full vernalization in this trial. The wide range of variation for heading time among the $\mathrm{DH}$ lines, and the low CDD temperatures in this trial were consistent with insufficient vernalization (Table 1). These circumstances are not uncommon 21 in the region.

The dynamic relationship of yield with heading date (Fig. 1, Fig. 2) was presumably, a consequence of different conditions of water availability during grain filling. At LE01, the temperatures were highest, and precipitation the lowest, during winter and spring (as most of the $128 \mathrm{~mm}$ of spring rainfall fell on a single day, at the end of the season). These data are 
1 consistent with the occurrence of terminal stress and, hence, of less favourable conditions for

2 late heading genotypes. At VA02, on the other hand, rainfall was evenly distributed over the

3 entire season and temperatures were lower than at the other trials, especially during grain

4 filling. Therefore, VA02 conditions were comparatively better for late genotypes.

Five main effect QTL for grain yield and three for GxE interaction were identified

6 (Table 3, Fig. 3a). These results reveal the important role of heading date, and heading date

7 QTL, in determining yield and its GxE interaction. The main effect yield QTL were located in 8 the following regions:

$9-\quad$ Y1, on the long arm of chromosome 3H (bin 13). There are several reports of QTL for grain yield in this region (Hayes et al. 1993, Thomas et al. 1995, Bezant et al. 1997, Powell et al. 1997, Yin et al. 1999, Marquez-Cedillo et al. 2001). QTL were also found in this region for ear grain weight and thousand grain weight (Bezant et al. 1997). The semi dwarf gene denso (Laurie et al. 1993), which affects many agronomic traits (Barua et al. 1993, Powell et al. 1985, Thomas et al. 1995), is located in this bin. However, neither parent of this cross is a denso semi-dwarf.

- Y2, Y3, Y4, on the long arm of chromosome 5H. There is sufficient distance between them to consider them independent. Two of these QTL (Y2, Y3) are in the same bins (5 and 10, respectively) as two yield hot-spots described by Thomas (2003) that are present in at least four populations. Other yield-related traits for which QTL were found in bin 5 are kernel weight (Pillen et al. 2003) and heading date (Pan et al. 1994, Thomas et al. 1995). Y4 in, bins 12-14, is co-located with a grain yield QTL reported by MarquezCedillo et al. (2001), a heading date QTL (Pan et al. 1994), and a lodging resistance QTL (Backes et al. 1995). Vrn-H1, the main gene governing vernalization sensitivity, was assayed using diagnostic primers for HvBM5 and lies between Y3 and Y4. 
Therefore, vernalization sensitivity is not a determinant of yield in this population in this sample of environments.

- $\quad Y 5$, located in the centromeric region of chromosome $7 \mathrm{H}$, bin 7 . In this zone, Hayes et al. (1993) found a QTL for grain yield, and Laurie et al. (1995) one for heading date. Other QTL reported in this region for yield-related traits were plant height (de la Pena et al. 1999, Marquez-Cedillo et al. 2001) and root length (Jefferies et al. 1999).

The significant interaction found between $Y 2$ and $Y 4$ was caused by higher-thanexpected yield produced by the combination of Mogador alleles at both loci. These QTL are both on chromosome $5 \mathrm{H}$, but they are distant enough to segregate independently. However, the presence of another QTL between them (Y3), in repulsion, may affect the power of tests in this region.

Several regions also showed QTL x E interaction (Fig. 3b):

- Bmac132, in the centromeric region of chromosome $2 \mathrm{H}$ (bin 8), is coincident with the earliness per se locus eps2S or Eam6 (Laurie et al. 1995, Franckowiak and Konishi 2002, Horsley et al. 2006), whose effect is noticeable under both long- and short-day conditions. This was the most important region for heading time in autumn sowings in Beka x Mogador (Cuesta-Marcos et al. 2008) and in Beka x Logan (Moralejo et al. 2004). It is described as the one of the main heading date QTL under Australian field conditions, where cultivars are also exposed to natural (short) photoperiods during most of the growing season (Boyd et al. 2003).

- Bmag382, on the long arm of chromosome $1 \mathrm{H}$ (bins 12-13) is coincident with the position of the photoperiod response gene $\mathrm{Ppd}-\mathrm{H} 2$, which causes differences in heading date under short photoperiod conditions (Pan et al. 1994, Laurie et al. 1995, Boyd et al. 2003, Francia et al. 2004). This QTL is a major determinant of heading date under autumn sowing conditions in Spain for this population (Cuesta-Marcos et al. 2008). 
The analysis that surveyed the effect of all markers on yield, including their interaction

2 with Cycle, detected additional QTL in the vicinity of the following markers:

$3-$ HvM40, located on the short arm of chromosome 4H (bin 2). The LOD is slightly under 4 the significance threshold in the CIM analysis (Fig. 3a). No yield QTL has previously been reported in this region, but QTL for heading date were found in this population (Cuesta-Marcos et al. 2008), and in Steptoe x Morex (Hayes et al. 1993). Zhu et al. (1999) and Marquez-Cedillo et al. (2001) found a QTL for plant height, which is a trait usually associated with yield under drought conditions (Ceccarelli et al. 1991; Teulat et al. 2001).

- E41M47-d maps on the long arm of chromosome 4H, just below the centromere (bins 67). Grain yield QTLs in this area were found by Marquez-Cedillo et al. (2001), Long et al. (2003) and Pillen et al. (2003). In our study, its effect was observable only in the Late heading class (Fig. 5). Hence, this QTL may be related to a mechanism that affects yield when its relationship with heading date is negative, most likely in a situation of terminal water stress.

- HvZCCT, in the long arm of chromosome 4H (bin 13) is the allele-specific marker for the vernalization gene $\mathrm{Vrn}-\mathrm{H} 2$. If this gene is a determinant of grain yield, its effects may be via plant architecture. Vernalization affects not only heading time, but also the relative duration of phases of plant development. Thus, different combinations of vernalization alleles might affect the balance of number of tillers and spike size, even within the same maturity group (Karsai et al. 2006). These differences in plant architecture could result in differences in grain yield. This hypothesis needs validation in other sets of materials.

This population displayed an impressive degree of phenotypic variation for heading date - on average 18 days. The scatterplot shown in Fig. 2 reveals that this range is wide enough to 
1 encompass the optimum heading date to maximize yield for this population in this range of

2 environments. It is also clear from the figure that higher yield potential, and variability, are

3 found in the intermediate maturity group. It is possible that lines which are too early maturing

4 are not able to take full advantage of spring rains, although they could be a safe bet from an

5 agronomic point of view. Late lines, on the other hand, with their longer vegetative phase, can

6 take advantage of spring rainfall, and thus accumulate more biomass to achieve higher yield

7 potential. However, their yield can be reduced to a greater extent because of the drought stress

8 that commonly occurs at the end of the crop cycle. All things considered, intermediate

9 heading dates are most likely to maximize yield.

Other studies carried out in the Mediterranean region, mainly by ICARDA researchers,

11 showed that the optimum heading date is one that is early enough to allow for grain filling and drought avoidance but late enough to avoid cold damage (van Oosterom and Acevedo 1992a). Plant ideotypes proposed by these authors were early heading spring types or winter types with moderately early heading (van Oosterom and Acevedo 1992b).

The range of heading dates in this population is representative of those found in the Spanish Barley Breeding Programme, in trials carried out at the same locations. In these trials, two cultivars are used regularly as early and late checks, to define the acceptable heading date window for the materials in the programme. The flowering date of these checks, sown in neighbour plots, was very similar to the extreme lines of the Beka x Mogador population. Our results corroborate the experience gained over the years by the Spanish Barley Breeding 21 Programme, suggesting that the optimum heading time for the inland plains of Spain is intermediate. Thus, we can conclude that the wide range of heading dates displayed by this population, and the diversity of environments encountered, provided a useful framework for the detection of yield QTL under Mediterranean conditions. 
This work was supported by the Spanish Ministry of Education and Research (Projects

AGL2001-2289, including a scholarship granted to Alfonso Cuesta-Marcos, and AGL2004-

05311) and by the European Regional Development Fund.

\section{References}

Backes, G., A. Graner, B. Foroughi-Wehr, G. Fischbeck, G. Wenzel, and A. Jahoor, 1995: Localization of quantitative trait loci (QTL) for agronomic important characters by the use of a RFLP map in barley (Hordeum vulgare L.). Theor. Appl. Genet. 90, 294-302.

Barua, U. M., K. J. Chalmers, W. T. B. Thomas, C. A. Hackett, V. Lea, P. Jack, B. P. Forster, R. Waugh, and W. Powell, 1993: Molecular mapping of genes determining height, time to heading, and growth habit in barley (Hordeum vulgare ). Genome 36, 1080-1087.

Bezant, J., D. Laurie, N. Pratchett, J. Chojecki, and M. Kearsey, 1997: Mapping QTL controlling yield and yield components in spring barley (Hordeum vulgare L.) cross. Heredity 77, 64-73.

Boyd, W. J. R. 1996: Developmental variation, adaptation and yield determination in spring barley. Proceedings of V International Oat Congress and VII Barley Genetics Symposium, p. 276-283.

Boyd, W. J. R., C. D. Li, C. R. Grime, M. Cakir, S. Potipibool, L. Kaveeta, S. Men, M. R. J. Kamali, A. R. Barr, D. B. Moody, R. C. M. Lance, S. J. Logue, H. Raman, and B. J. Rea, 2003: Conventional and molecular genetic analysis of factors contributing to variation in the timing of heading among spring barley (Hordeum vulgare L.) genotypes grown over a mild winter growing season. Aust. J. Agric. Res. 54, 1277-1301.

Ceccarelli, S., E. Acevedo, and S. Grando, 1991: Breeding for yield stability in unpredictable environments: Single traits, interaction between traits, and architecture of genotypes. Euphytica 56, 169-185.

Cuesta-Marcos, A., E. Igartua, F. J. Ciudad, P. Codesal, J. R. Russell, J. L. Molina-Cano, M. Moralejo, P. Szücs, M. P. Gracia, J. M. Lasa, and A. M. Casas, 2008: Heading date QTL in a spring $\mathrm{x}$ winter barley cross evaluated in Mediterranean environments. Mol. Breeding, DOI 10.1007/s11032-007-9145-3.

de la Pena, R. C., K. P. Smith, F. Capettini, G. J. Muehlbauer, M. Gallo-Meagher, R. DillMacky, D. A. Somers, and D. C. Rasmusson, 1999: Quantitative trait loci associated with resistance to Fusarium head blight and kernel discoloration in barley. Theor. Appl. Genet. 99, 561-569.

Francia, E., F. Rizza, L. Cattivelli, A. M. Stanca, G. Galiba, B. Tóth, P. M. Hayes, J. S. Skinner, and N. Pecchioni, 2004: Two loci on chromosome 5H determine low-temperature 
tolerance in a 'Nure' (winter) x 'Tremois' (spring) barley map. Theor. Appl. Genet. 108, 670-680.

Franckowiak, J. D., and T. Konishi, 2002: Early maturity 6, Eam6. Barley Genet. Newsl. 32, 86-87.

Hayes, P. M., B. H. Liu, S. J. Knapp, F. Chen, B. Jones, T. Blake, J. Franckowiak, D. Rasmusson, M. Sorrells, S. E. Ullrich, D. Wesenberg, and A. Kleinhofs, 1993: Quantitative trait locus effects and environmental interaction in a sample of North American barley germ plasm. Theor. Appl. Genet. 87, 392-401.

Horsley, R. D., D. Schmierer, C. Maier, D. Kudrna, C. A. Urrea, B. J. Steffenson, P. B. Schwarz, J. D. Franckowiak, M. J. Green, B. Zhang, and A. Kleinhofs, 2006: Identification of QTLs associated with Fusarium head blight resistance in barley accession CIho 4196. Crop Sci. 46, 145-156.

Jefferies, S. P., A. R. Barr, A. Karakousis, J. M. Kretschmer, S. Manning, K. J. Chalmers, J. C. Nelson, A. K. M. R. Islam, and P. Langridge, 1999: Mapping of chromosome regions conferring boron toxicity tolerance in barley (Hordeum vulgare L.). Theor. Appl. Genet. 98, 1293-1303.

Jiang, C. J., and Z. B. Zeng, 1995: Multiple-trait analysis of genetic-mapping for quantitative trait loci. Genetics 140, 1111-1127.

Kao, C. H., Z. B. Zeng, and R. D. Teasdale, 1999: Multiple interval mapping for quantitative trait loci. Genetics 152, 1203-1216.

Karsai, I., K. Mészáros, P. Szücs, P. M. Hayes, L. Láng, and Z. Bedö, 1999: Effects of loci determining photoperiod sensitivity (Phd-H1) and vernalization response (Sh2) on agronomic traits in the 'Dicktoo' $\times$ 'Morex' barley mapping population. Plant Breed. 118, 399-403.

Karsai, I., K. Mészáros, P. Szűcs, P. M. Hayes, L. Láng, and Z. Bedő, 2006: The influence of photoperiod on the Vrn-H2 locus $(4 \mathrm{H})$ which is a major determinant of plant development and reproductive fitness traits in a facultative $\times$ winter barley (Hordeum vulgare L.) mapping population. Plant Breed. 125, 468-472.

Lander, E., and D. Botstein, 1989: Mapping mendelian factors underlying quantitative traits using RFLP linkage maps. Genetics 121, 185-199.

Laurie, D. A., N. Pratchett, C. Romero, E. Simpson, and J. W. Snape, 1993: Assignment of the denso dwarfing gene to the long arm of chromosome $3(3 \mathrm{H})$ of barley by use of RFLP markers. Plant Breed. 111, 198-203.

Laurie, D. A., N. Pratchett, J. H. Bezant, and J. W. Snape, 1994: Genetic analysis of a photoperiod response gene on the short arm of chromosome $2(2 \mathrm{H})$ of Hordeum vulgare (barley). Heredity 72, 619-627.

Laurie, D. A., N. Pratchett, J. H. Bezant, and J. W. Snape, 1995: RFLP mapping of five major genes and eight quantitative trait loci controlling flowering time in a winter $\mathrm{x}$ spring barley (Hordeum vulgare L.) cross. Genome 38, 575-585.

Long, N. R., S. P. Jefferies, P. Warner, A. Karakousis, J. M. Kretschmer, C. Hunt, P. Lim, P. J. Eckermann, and A. R. Barr, 2003: Mapping and QTL analysis of the barley population Mundah x Keel. Aust. J. Agric. Res. 54, 1163-1171.

Marquez-Cedillo, L. A., P. M. Hayes, A. Kleinhofs, W. G. Legge, B. G. Rossnagel, K. Sato, S. E. Ullrich, and D. M. Wesenberg, 2001: QTL analysis of agronomic traits in barley based 
on the doubled haploid progeny of two elite North American varieties representing different germplasm groups. Theor. Appl. Genet. 103, 625-637.

Moralejo, M., J. S. Swanston, P. Muñoz, D. Prada, M. Elia, J. R. Russell, L. Ramsay, L. Cistué, P. Codesal, A. M. Casas, I. Romagosa, W. Powell, and J. L. Molina-Cano, 2004: Use of new EST markers to elucidate the genetic differences in grain protein content between European and North American two-rowed malting barleys. Theor. Appl. Genet. 110, 116-125.

Pan, A., P. M. Hayes, F. Chen, T. H. H. Chen, T. Blake, S. Wright, I. Karsai, and Z. Bedö, 1994: Genetic analysis of the components of winterhardiness in barley (Hordeum vulgare L). Theor. Appl. Genet. 89, 900-910.

Pillen, K., A. Zacharias, and J. Léon, 2003: Advanced backcross QTL analysis in barley (Hordeum vulgare L). Theor. Appl. Genet. 107, 340-352.

Powell, W., P. D. S. Caligari, W. T. B. Thomas, and J. L. Jinks, 1985: The effects of major genes on quantitatively varying characters in barley. 2 . The denso and daylength response loci. Heredity 54, 349-352.

Powell, W., W. T. B. Thomas, E. Baird, P. Lawrence, A. Booth, B. Harrower, J. W. McNicol, and R. Waugh, 1997: Analysis of quantitative traits in barley by the use of amplified fragment length polymorphisms. Heredity 79, 48-59.

Rebetzke, G. J., and R. A. Richards, 2000: Gibberellic acid-sensitive dwarfing genes reduce plant height to increase kernel number and grain yield of wheat. Aus. J. Agric. Res. 51, 235245.

Slafer, G. A., 2003: Genetic basis of yield as viewed from a crop physiologist's perspective. Ann. Appl. Biol. 142, 117-128.

Teulat, B., O. Merah, I. Souyris, and D. This, 2001: QTLs for agronomic traits from a Mediterranean barley progeny grown in several environments. Theor. Appl. Genet. 103, 774-787.

Thomas, W. T. B., W. Powell, R. Waugh, K. J. Chalmers, U. M. Barua, P. Jack, V. Lea, B. P. Forster, J. S. Swanston, R. P. Ellis, P. R. Hanson, and R. C. M. Lance, 1995: Detection of quantitative trait loci for agronomic, yield, grain and disease characters in spring barley (Hordeum vulgare L.). Theor. Appl. Genet. 91, 1037-1047.

Thomas, W. T. B., 2003: Prospects for molecular breeding of barley. Ann. Appl. Biol. 142, 112.

van Oosterom, E. J., and E. Acevedo, 1992a: Adaptation of barley (Hordeum vulgare L ) to harsh Mediterranean environments. I. Morphological traits. Euphytica 62, 1-14.

van Oosterom, E. J., and E. Acevedo, 1992b: Adaptation of barley (Hordeum vulgare L ) to harsh Mediterranean environments. III. Plant ideotype and grain yield. Euphytica 62, 29-38.

Voltas, J., F. van Eeuwijk, E. Igartua, L. García del Moral, J. L. Molina-Cano, and I. Romagosa, 2002: Genotype by environment interaction and adaptation in barley breeding: basic concepts and methods of analysis. In Barley Science: Recent Advances from Molecular Biology to Agronomy of Yield and Quality. Eds G. A. Slafer, J. L. Molina-Cano, R. Savin, J. L. Araus, I. Romagosa,. New York: Food Product Press, pp. 205-241.

Wang, S., C. J. Basten and Z. B. Zeng, 2005: Windows QTL Cartographer 2.5. North Carolina State University, (http://www.statgen.ncsu.edu/qtlcart/WQTLCart.htm) 
1 Worland, A. J., A. Borner, V. Korzun, W.M. Li, S. Petrovic, and E.J. Sayers, 1998: The 2 influence of photoperiod genes on the adaptability of European winter wheats (Reprinted 3 from Wheat: Prospects for global improvement, 1998). Euphytica 100, 385-394.

4 Yin, X., P. Stam, C. Johan Dourleijn, and M. J. Kropff, 1999: AFLP mapping of quantitative 5 trait loci for yield-determining physiological characters in spring barley. Theor. Appl. 6 Genet. 99, 244-253.

7 Zeng, Z. B., 1994: Precision mapping of quantitative trait loci. Genetics 136, 1457-1468.

8 Zhu, H., L. Gilchrist, P. Hayes, A. Kleinhofs, D. Kudrna, Z. Liu, L. Prom, B. Steffenson, T. 9 Toojinda, and H. Vivar, 1999: Does function follow form? Principal QTLs for Fusarium 10 head blight (FHB) resistance are coincident with QTLs for inflorescence traits and plant 11 height in a doubled haploid population of barley. Theor. Appl. Genet. 99, 1221-1232. 
2 Table 1. Sowing dates and environmental conditions (seasonal cumulative precipitation and 3 average temperature values) in the five autumn-sown field trials carried out in this study.

4

\begin{tabular}{|c|c|c|c|c|c|c|c|c|}
\hline \multirow{2}{*}{ Trial } & \multirow{2}{*}{$\begin{array}{c}\text { Sowing } \\
\text { date }\end{array}$} & \multicolumn{3}{|c|}{ Precipitation (mm) } & \multicolumn{3}{|c|}{ Temperature $\left({ }^{\circ} \mathrm{C}\right)$} & \multirow[t]{2}{*}{$\mathrm{CDD} \dagger$} \\
\hline & & Fall & Winter & Spring & Fall & Winter & Spring & \\
\hline LE01 & $19-12-00$ & 95 & 50 & 128 & 9.8 & 9.3 & 19.1 & na \\
\hline ZA01 & $21-11-00$ & 83 & 67 & 47 & 10.6 & 8.1 & 16.9 & 434 \\
\hline LE02 & $01-12-01$ & 100 & 67 & 202 & 7.1 & 7.1 & 16.1 & na \\
\hline VA02 & 19-11-01 & 111 & 107 & 137 & 6.2 & 6.5 & 14.5 & 933 \\
\hline HU03 & 04-11-02 & 165 & 175 & 106 & 9.5 & 6.7 & 15.3 & 693 \\
\hline
\end{tabular}


1 Table 2. Days to heading and grain yield of $120 \mathrm{DH}$ lines of the Beka $\mathrm{x}$ Mogador barley

2 population, in the five autumn-sown field trials carried out in this study.

3

\begin{tabular}{|c|c|c|c|c|c|c|c|c|c|c|c|}
\hline \multirow[t]{3}{*}{ Trial } & \multicolumn{5}{|c|}{ Yield $\left(\mathrm{kg} \mathrm{ha}^{-1}\right)$} & \multicolumn{6}{|c|}{ Days to heading (from January 1st) } \\
\hline & Parents & \multicolumn{4}{|c|}{ Offspring (DH lines) } & \multicolumn{2}{|c|}{ Parents } & \multicolumn{4}{|c|}{ Offspring (DH lines) } \\
\hline & BEK MOG & Mean & $\sigma$ & Min. & Max. & BEK & & Mean & $\sigma$ & Min. & Max. \\
\hline LE0 & $05 \quad 4661$ & 4693 & 518.5 & & & 104 & & & 4.11 & 95.0 & \\
\hline ZA & 83 & & & & & 99.4 & 104 & 99.1 & 4.40 & 89.5 & 112.5 \\
\hline & & & & & & - & & - & - & - & - \\
\hline & 4651 & 4829 & 557 & 3510 & & 122.1 & & 123.5 & 3.79 & 116.1 & 131.8 \\
\hline HU03 & $4200 \quad 4594$ & 4422 & 497.9 & 3195 & 5748 & 104.4 & 106.9 & 106.2 & 4.22 & 97.0 & 114.2 \\
\hline
\end{tabular}

4

5

6

7

8

9 
1 Table 3. Grain Yield QTL detected for the average yield of $120 \mathrm{DH}$ lines of the Beka $\mathrm{x}$

2 Mogador barley population tested in 5 environments. LOD scores correspond to the CIM 3 analysis. Multiple Interval Mapping was used to calculate effects and $\mathrm{R}^{2}$.

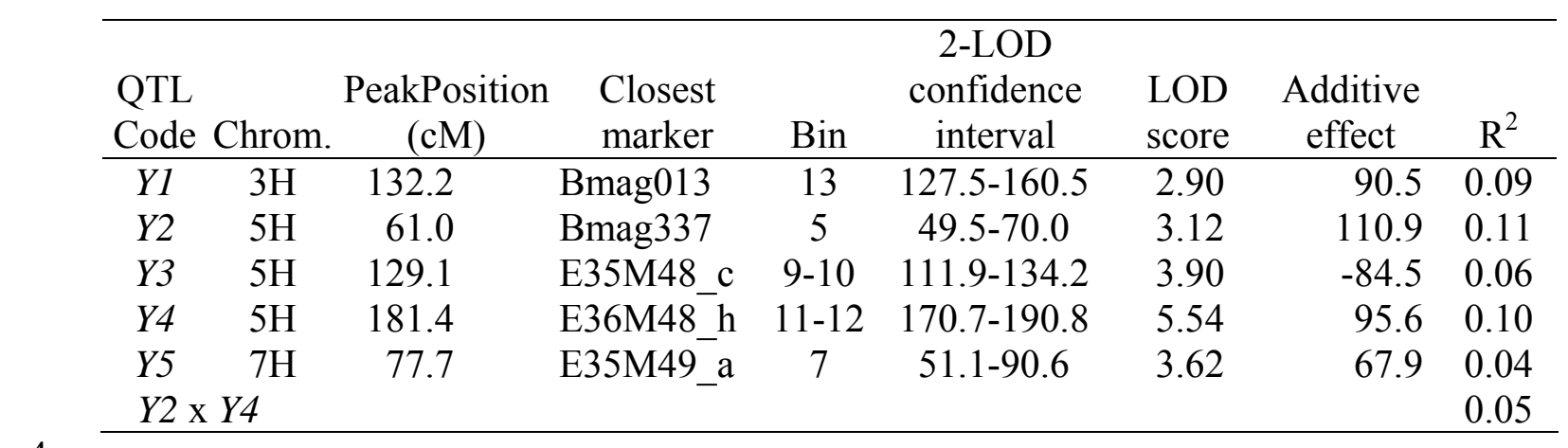

6

7

8

9

10

11

12

13

14

15 
1 Table 4. Average yield and heading date of the 120 barley DH lines of the Beka $\mathrm{x}$ Mogador

2 barley population, divided in three heading time classes defined by the allelic combination at 3 Bmag382 (Ppd-H2 region) and Bmac132 (Eam6 region).

4

\begin{tabular}{|c|c|c|c|c|c|c|}
\hline & \multirow{2}{*}{$\begin{array}{l}\text { Bmag382 } \\
(\text { Ppd-H2) }\end{array}$} & \multirow{2}{*}{$\begin{array}{c}\text { Bmac132 } \\
\text { (Eam6) }\end{array}$} & \multirow{2}{*}{$\begin{array}{l}\text { no. } \\
\text { lines }\end{array}$} & \multicolumn{2}{|c|}{ Yield } & \multirow[b]{2}{*}{ Days to heading } \\
\hline & & & & Mean & $\sigma$ & \\
\hline & & & & \multicolumn{2}{|c|}{$\left(\mathrm{kg} \mathrm{ha}^{-1}\right)^{*}$} & (days since January $1^{\text {st }}$ ) \\
\hline Early & Beka & Mogador & 35 & $4538 \mathrm{a}$ & 220 & $103.5 \mathrm{a}$ \\
\hline Intermediate & $\begin{array}{c}\text { Mogador } \\
\text { Beka }\end{array}$ & $\begin{array}{c}\text { Mogador } \\
\text { Beka }\end{array}$ & 58 & $4587 \mathrm{a}$ & 335 & $108.4 \mathrm{~b}$ \\
\hline Late & Mogador & Beka & 27 & $4295 \mathrm{~b}$ & 298 & $112.3 \mathrm{c}$ \\
\hline
\end{tabular}

*Means separation LSD; $\alpha=0.05$

5

6

7 
1 Table 5. Analysis of variance of the yield QTL and their significant interactions, for the whole

2 set of lines and also for three subsets of lines according to heading time classes defined by the

3 allelic combinations at Bmag382 and Bmac132 (Cycle). Closest markers to the QTL peaks

4 detected in the CIM analysis are used. Mean squares of yield values, derived from Type I

5 sums of squares, expressed in $\mathrm{q} \mathrm{ha}^{-1}$.

6

7

8

\begin{tabular}{|c|c|c|c|}
\hline Source of variation & DF & Mean squares & sign. $\mathrm{F}$ \\
\hline GENOTYPE (G) & 119 & 478 & $* *$ \\
\hline Cycle & 2 & 4211 & $* *$ \\
\hline HvZCCT $*$ Cycle & 3 & 1535 & $* *$ \\
\hline HVM40 * Cycle & 3 & 1438 & $* *$ \\
\hline E41M47_d*Cycle & 3 & 1042 & $* *$ \\
\hline E36M48_h (Y4) * Cycle & 3 & 1312 & $* *$ \\
\hline E35M49_a (Y5)* Cycle & 3 & 638 & $*$ \\
\hline Bmag013 $(\mathrm{Y} 1) *$ Cycle & 3 & 933 & $* *$ \\
\hline Bmag337 (Y2) * Cycle & 3 & 705 & $*$ \\
\hline Genotype (residual) & 93 & 267 & $*(0.045)$ \\
\hline ENVIRONMENT (E) & 4 & 92122 & \\
\hline $\mathrm{G} * \mathrm{E}$ & 475 & 207 & $* *$ \\
\hline Cycle $* E$ & 8 & 1940 & $* *$ \\
\hline $\operatorname{Bmag} 337(\mathrm{Y} 2) * \mathrm{E}$ & 4 & 1399 & $* *$ \\
\hline $\mathrm{G} * \mathrm{E}$ (residual) & 463 & 159 & $* *$ \\
\hline ERROR & 949 & 80 & \\
\hline
\end{tabular}


1 Figure 1. Scatter plots of the heading dates from January $1^{\text {st }}\left(\mathrm{X}\right.$-axis) and yield in $\mathrm{kg} \mathrm{ha}^{-1}(\mathrm{Y}-$ 2 axis) in four field trials. The $120 \mathrm{DH}$ lines of the barley population Beka $\mathrm{x}$ Mogador are 3 indicated by dots. Lines show the linear trend between the two variables. $\mathrm{R}^{2}$ of the linear 4 regressions are also shown. $\mathrm{F}$ value of the linear regression significant at $* \mathrm{P}<0.05, * * \mathrm{P}<$ $5 \quad 0.01, * * * \mathrm{P}<0.001$.

6 Figure 2. Relationship between heading date and yield for the averages of $120 \mathrm{DH}$ lines of the 7 Beka x Mogador barley population in four (heading date) or five (yield) environments. $\mathrm{R}^{2}$ of 8 the quadratic regression is also shown. Symbols stand for haplotypes at the two main heading 9 date loci for each line of this population, represented by markers Bmag382 and Bmac132.

10 Figure 3. Results of composite interval mapping for grain yield at five field trials. Scans for a) 11 grain yield main effect, CIM analysis with a 2.7 LOD threshold; b) genotype-by-environment 12 interaction, CIM scan (full line) and IM scan (dotted line) analysis for QTL; LOD threshold 13 (5.1) corresponds only to IM.

14 Figure 4. QTL x Environment interaction for yield in the Beka x Mogador barley population. 15 Additive yield effect of markers significant for QTLxE interaction at the five field trials. 16 Positive values indicate higher yield of lines carrying the Mogador allele.

17 Figure 5. Yield QTL in the Beka $\mathrm{x}$ Mogador barley population, divided by heading time 18 (cycle) classes. Additive effect of the QTL detected in the QTL x cycle analysis, at the 19 different heading time classes. Positive values indicate higher yield of lines carrying the 20 Mogador allele. 

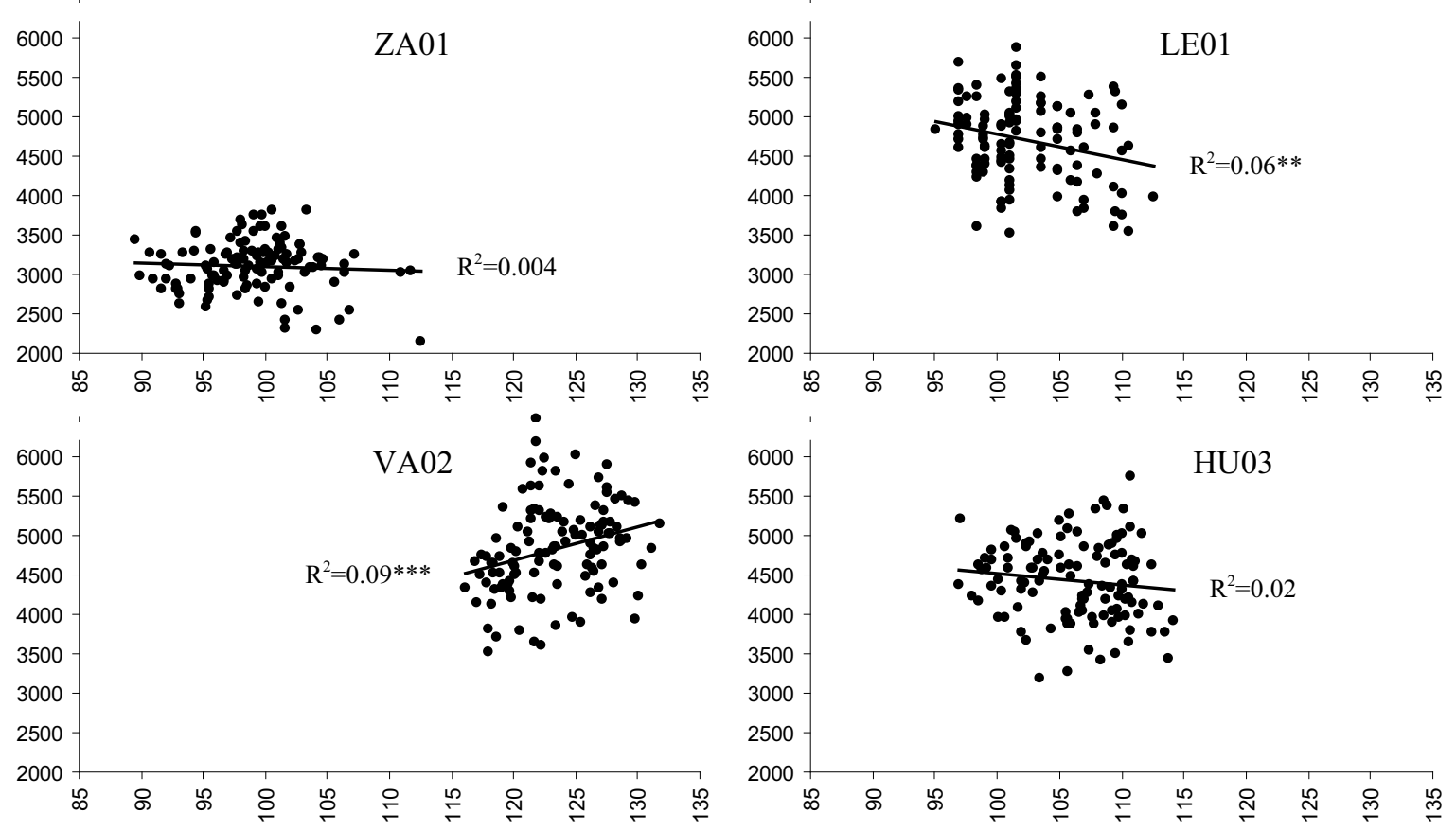


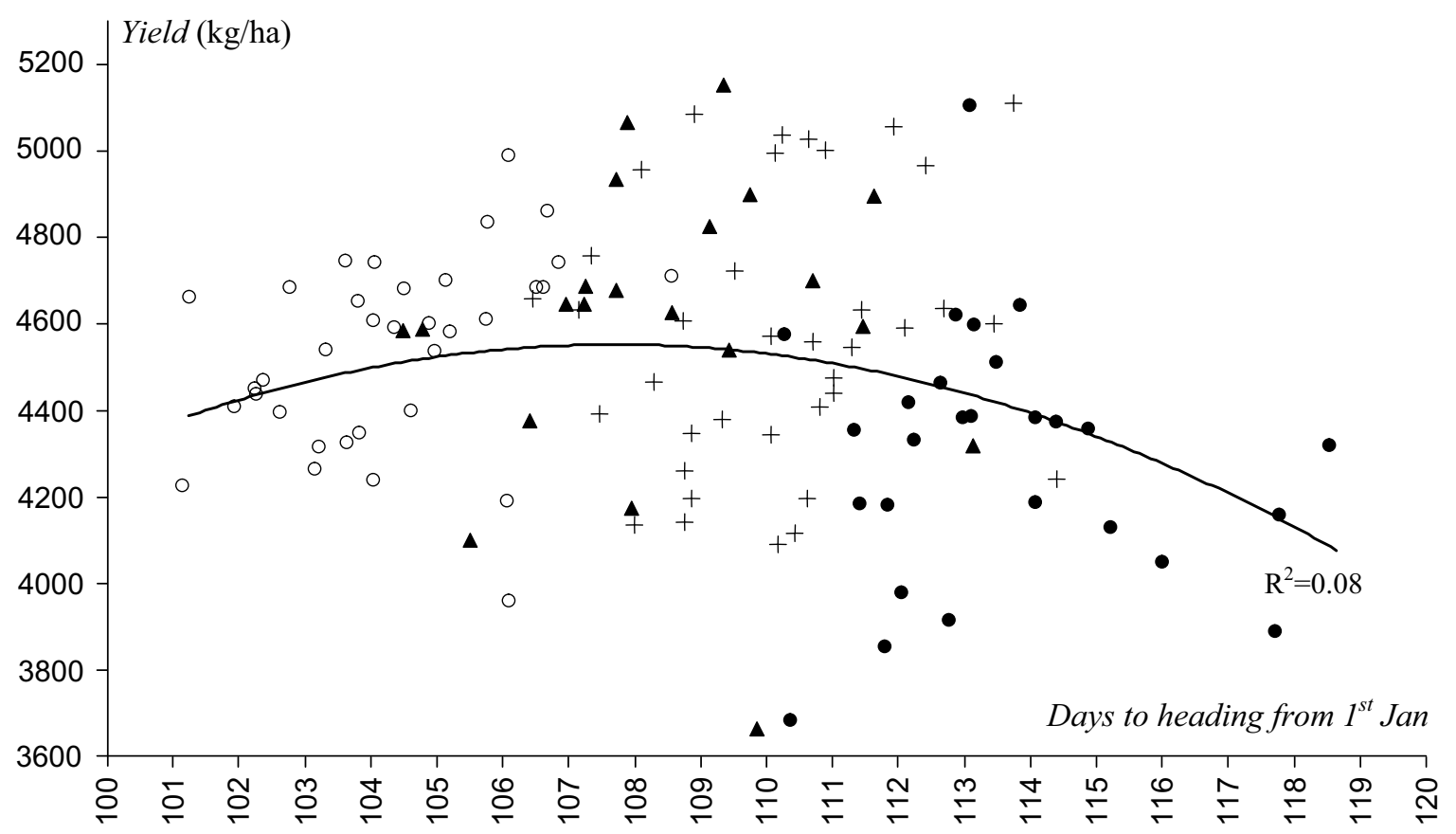

○ Early genotypes, $B M+$ Intermediate-Late genotypes, $B B$

\ Intermediate-Early genotypes, $M M$

- Late genotypes, $M B$ 

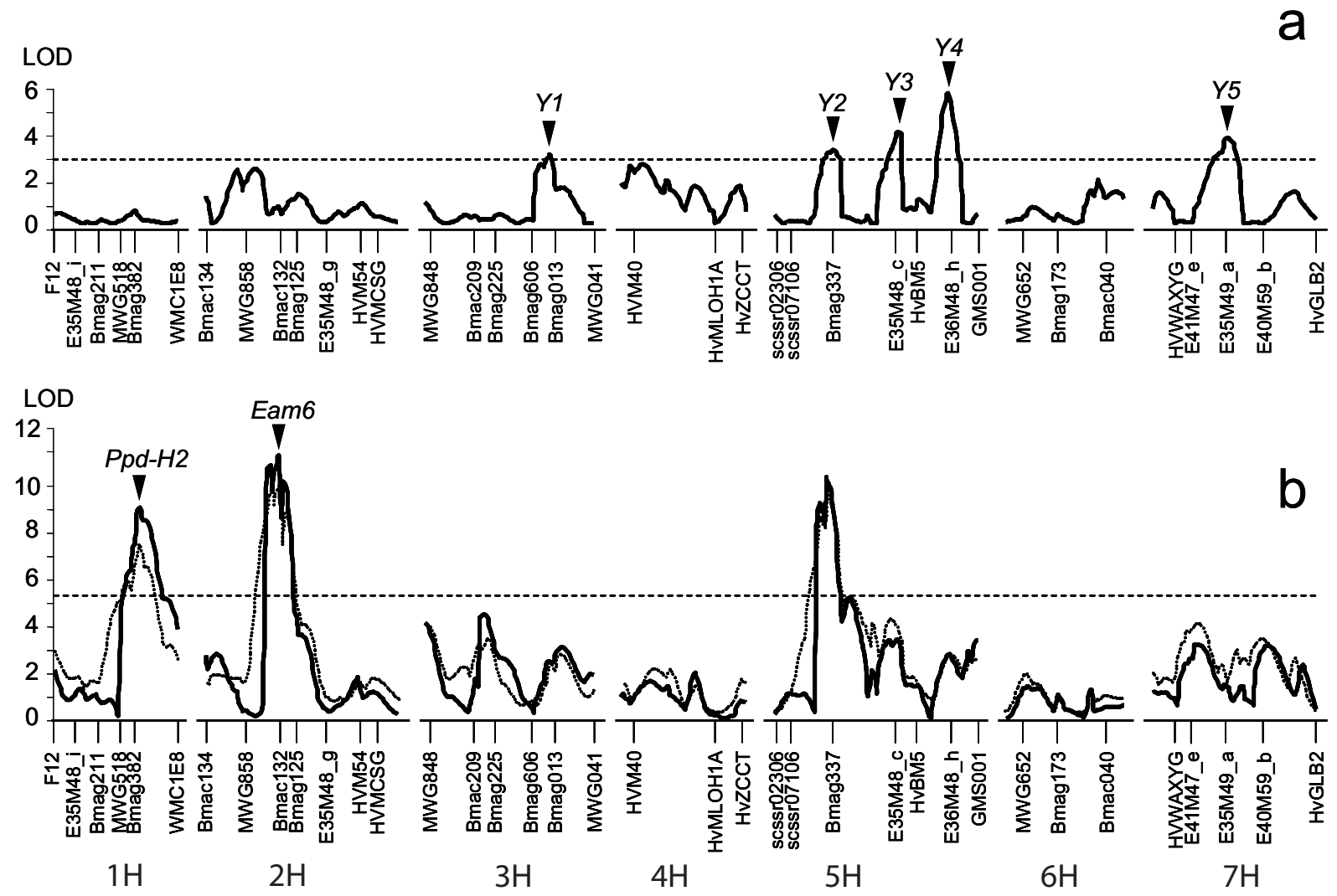


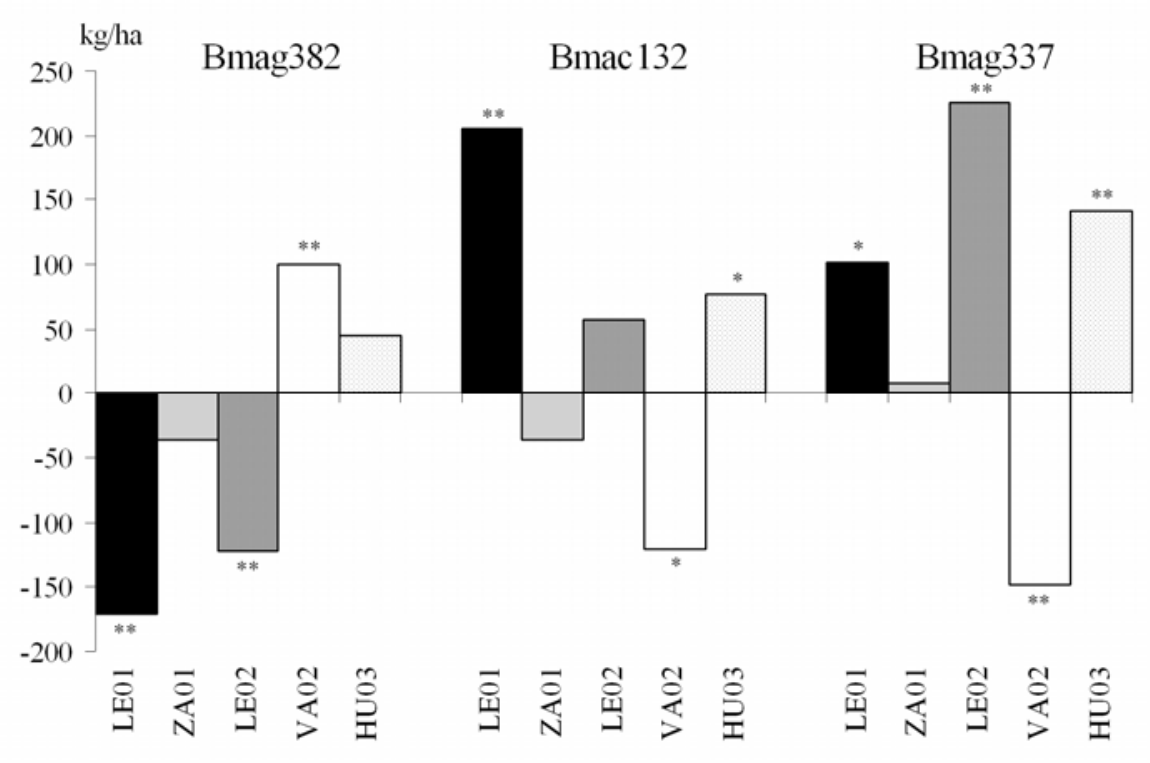

1 


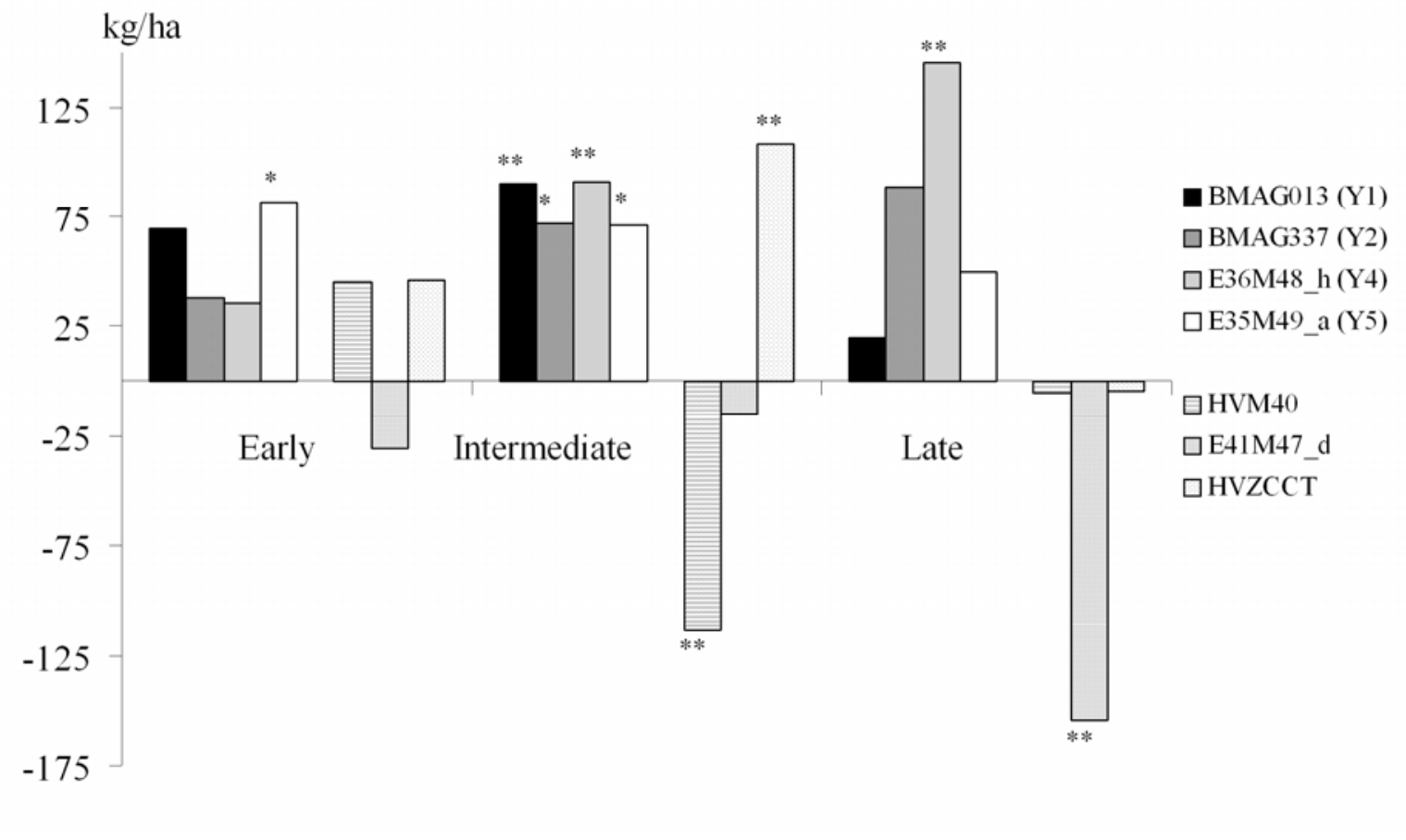

